\title{
O NOVO CORONAVÍRUS E OS IMPACTOS PSICOLÓGICOS DA QUARENTENA
}

The new coronavirus and the psychological impacts of the quarantine

El nuevo coronavirus y los impactos psicológicos de la cuarentena

Cristina Silvana da Silva Vasconcelos ${ }^{* 1}$, Izabella de Oliveira Feitosa ${ }^{2}$, Plácido Lucio Rodrigues Medrado ${ }^{3}$, Ana Paula Barbosa de Brito ${ }^{1}$

${ }^{1}$ Fundação Escola de Saúde Pública, Palmas, Brasil.

${ }^{2}$ Superitendência de Atenção e Vigilância em Saúde, Secretaria Municipal de Saúde, Palmas, Brasil.

${ }^{3}$ Núcleo de Assistência Social, Secretaria de Assistência Social, Porto Nacional, Brasil.

*Correspondência:e-mail: cristinassvasconcelos@gmail.com.

Artigo recebido em 03/04/2020 aprovado em 21/04/2020 publicado em 22/04/2020.

\section{RESUMO}

O ano de 2020 iniciou com a notícia do surgimento, em dezembro de 2019, na cidade chinesa de Wuhan, de um novo coronavírus causador da Covid-19 - uma doença altamente transmissível e, em alguns casos, letal. A pandemia do novo coronavírus trouxe efeitos sociais, econômicos e psicológicos em todo o mundo. Diante disso, especialistas recomendaram a quarentena como principal forma de impedir a propagação do vírus. Apesar de serem medidas necessárias deve-se levar em consideração a saúde mental das pessoas submetidas a esse período. Este estudo tem como objetivo realizar uma análise sobre os efeitos da quarentena e propor estratégias para enfrentá-la, além de minimizar seus efeitos. Trata-se de uma revisão narrativa de artigos publicados entre os anos 2018 e 2020, nas plataformas Biblioteca Virtual em Saúde, PubMed e no Google Acadêmico. Os achados apontam que a quarentena pode desencadear sintomas psicológicos, sendo os sintomas mais comuns ansiedade, tristeza e raiva, podendo ser pontuais ou se estenderem após o término do isolamento. Contudo, existem estratégias quando adotadas em conjunto, podem minimizar os efeitos psicológicos do isolamento e fazer desse momento menos adoecedor.

Palavras chave: coronavírus, quarentena, saúde mental.

\section{ABSTRACT}

The year 2020 began with the news of the appearance in December 2019 in the Chinese city of Wuhan of a new coronavirus that causes Covid-19 - a highly communicable disease and in some cases lethal. The new coronavirus pandemic has brought social, economic and psychological effects worldwide. Given this, experts recommended quarantine as the main way to prevent the spread of the virus. Despite being necessary measures, the mental health of the people submitted to this period must be taken into account. This study aims to carry out a critical analysis of the effects of quarantine and to propose strategies to face it, in addition to minimizing its effects. This is a literature review of articles between the years 2018 and 2020, on the Virtual Health Library, PubMed and Google Scholar platforms. The findings indicate that quarantine can trigger psychological symptoms, the most common symptoms being anxiety, sadness and anger, which can be punctual or extend after the end of isolation. However, there are strategies when adopted together, which can minimize the psychological effects of isolation and make this moment less painful.

Key Words: coronavirus, quarantine, mental health.

\section{RESUMEN}

El año 2020 comenzó con la noticia de la aparición en diciembre de 2019 en la ciudad china de Wuhan de un nuevo coronavirus que causa Covid-19 - una enfermedad altamente transmisible y en algunos casos letal. La nueva pandemia de coronavirus ha traído efectos sociales, económicos y psicológicos en todo el mundo. Ante esto, los expertos recomendaron la cuarentena como la forma principal de prevenir la propagación del virus. A pesar de ser medidas necesarias, debe tenerse en cuenta la salud mental de las personas sometidas a este período. El objetivo de 
este estudio es realizar un análisis crítico de los efectos de la cuarentena y proponer estrategias para enfrentarla, además de minimizar sus efectos. Esta es una revisión de la literatura de artículos entre los años 2018 y 2020 sobre las plataformas de la Biblioteca Virtual en Salud, PubMed y Google Scholar. Los resultados indican que la cuarentena puede desencadenar síntomas psicológicos, siendo los síntomas más comunes la ansiedad, la tristeza y la ira, que pueden ser puntuales o extenderse después del final del aislamiento. Sin embargo, existen estrategias cuando se adoptan juntas, pueden minimizar los efectos psicológicos del aislamiento y hacer que este momento sea menos doloroso.

Palabras clave: coronavirus, cuarentena, salud mental.

\section{INTRODUÇÃO}

Um novo coronavírus causador de uma doença infecciosa (COVID-19) com alta transmissibilidade espalhou-se pelo mundo (Guo et al., 2020). Desde dezembro de 2019 até abril de 2020 foram confirmados 2.119.300 casos em diversos países, sendo 30.425 casos confirmados e 1.924 óbitos no Brasil (Brasil, 2020), tornando-se uma emergência de saúde pública de interesse internacional pela Organização Mundial da Saúde (OMS) (Guo et al., 2020).

Para conter a disseminação do vírus e possível colapso dos serviços de saúde, especialistas recomendaram uma série de medidas, entre elas, a quarentena ou popularmente chamada de isolamento social (Santos e Nascimento, 2014). Entende-se por quarentena como o período de restrição de circulação de indivíduos potencialmente expostos a determinado agente infeccioso (Smith e Freedman, 2020). Apesar de serem usados como sinônimos, para Coomes et al. (2020), quarentena difere de isolamento, pois, no primeiro termo, indivíduos saudáveis ou assintomáticos são isolados no período de incubação do vírus enquanto no segundo indivíduos com a infecção são isolados de pessoas saudáveis para evitar a transmissão.

No Brasil, o primeiro caso chegou em 26 de fevereiro de 2020 (Brasil, 2020), sendo decretado estado de quarentena a partir de 06 de fevereiro de 2020 por meio da Lei 13.979/2020. Desde então, os estados e municípios decretaram emergência de saúde pública e determinaram que locais como escolas, igrejas, boates, praças e outros lugares com aglomerações de pessoas fossem fechados. A população foi orientada a ficar em casa, em isolamento, sem contato com pessoas externas ao seu convívio, principalmente para não serem vetores do vírus para os indivíduos mais vulneráveis como idosos, imunodeprimidos e pessoas com afecções crônicas (Brasil, 2020).

A rápida progressão da epidemia e o excesso de informações disponíveis, por vezes contraditórias, é um campo facilitador para mudanças comportamentais impulsionadoras de adoecimento psicológico (Qian et al., 2020; Lima et al., 2020). Pode-se dizer que junto a pandemia do novo coronavírus surge um estado de pânico social global e a sensação de isolamento desperta angústia, insegurança, medo que podem se prolongar até mesmo após o controle do vírus (Hossain et al., 2020).

Apesar de ser uma medida muito utilizada em saúde pública para preservar a saúde física, é necessário pensar na saúde mental e bem-estar dos indivíduos submetidos a esse período de isolamento. Considerando isso, o objetivo do presente artigo é oferecer uma análise sobre os efeitos psicológicos da quarentena além de indicar estratégias de enfrentamento para minimizá-los.

Trata-se de uma revisão narrativa, onde não se estabeleceu critérios rígidos de inclusão ou exclusão de estudos, a busca por pesquisas não teve como objetivo esgotar as fontes de informação. Essa metodologia permite o desenvolvimento de artigos nos quais os autores analisam e interpretam de maneira 
mais abrangente estabelecendo relações com produções anteriores (Vosgerau e Romanowski, 2014). Foi realizada busca nas plataformas Biblioteca Virtual em Saúde (BVS), PubMed e no Google Acadêmico com os termos psychological effects of quarantine em artigos publicados entre 2018 e 2020. Foram inseridos na discussão artigos escritos em contexto de surtos ou epidemias.

\section{Impactos psicológicos}

Em um estudo realizado na Coréia do Sul, após o surto de Síndrome Respiratória por coronavírus, identificou-se que o nível de estresse diário e os sintomas de estresse pós-traumático podem ser fatores de risco para a depressão em pessoas em quarentena. Da mesma forma, identificaram fatores psicológicos como medo, tensão, raiva e desconfiança durante o isolamento (Kim et al., 2018). Esses fatores também foram percebidos em outro estudo realizado com profissionais da saúde no período de quarentena. Apontou-se que além do medo de infectar outra pessoa, os profissionais de saúde também evidenciaram sentimentos de raiva, aborrecimento, medo, frustração, culpa, solidão, e tristeza com o isolamento (Brooks et al., 2020).

Rubin e Wessely (2020) pontuam que as medidas de restrições impostas em Wuhan, na China, e seguidas pelos demais países, como forma de contenção da infecção, poderão ter efeitos psicológicos pontuais, mas também a longo prazo. Acrescentam que o medo, a ansiedade e o sentimento de raiva parecem ser os efeitos recentes mais comuns. E apontam que a sensação de "encarceramento" (simbologia para a quarentena como uma medida imposta) tende a maximizar tais efeitos.

Corroborando com Wang et al. (2020) que realizaram um estudo durante o surto inicial do COVID-19 na China com sua população geral. Foram entrevistadas 1210 pessoas de 194 cidades da China.
Este estudo encontrou que 53,8\% dos entrevistados avaliaram o impacto psicológico do surto como moderado ou grave; $16,5 \%$ relataram sintomas depressivos moderados a graves; $28,8 \%$ relataram moderados a graves sintomas de ansiedade e $8,1 \%$ relataram níveis de estresse moderado a grave. Ademais, a maioria dos entrevistados relataram ficar de 20 a 24 horas por dia em casa $(84,7 \%)$ e $75,2 \%$ afirmaram estar preocupados quanto a infecção pelo COVID-19 por seus familiares.

Os autores concluíram, a partir dos resultados demonstrados, que pode haver maior impacto psicológico nas mulheres e em grupos de estudantes, onde os níveis de estresse, ansiedade e depressão manifestaram-se de forma aumentada. No lado oposto, verificaram que pessoas que passaram a adotar práticas de prevenção em seu cotidiano e que consumiram informações em meios oficiais tiveram menor impacto psicológico (Wang et al., 2020).

Para Ho et al. (2020), as epidemias podem levar ao surgimento de sintomas psicológicos em pessoas que antes não os tinham, podendo agravar sintomas em pessoas com condições pré-existentes e causar sofrimento aos cuidadores de pessoas doentes. Os autores apontam, aindaque as emoções intensificadas podem motivar as pessoas a tomarem medidas ou remédios não comprovados que podem ser prejudiciais a sua saúde.

\section{Estratégias de enfrentamento}

A nova pandemia mundial (COVID-19) tem colocado em pauta principalmente a saúde física das pessoas como também a saúde mental visto que, para além de pensar nos efeitos psicológicos do isolamento, estudiosos têm debatido sobre as estratégias de enfrentamento para tornar o período de quarentena menos adoecedor (Wang et al., 2020).

Pensando nas consequências do isolamento, não podemos deixar de citar que além do impacto na 
economia e nas questões de ordem social (dificuldade de acesso a bens essenciais, por exemplo), evidenciase um abalo nas questões emocionais (individuais). Assim sendo, a China em 27 de janeiro do presente ano foi o primeiro país a pensar em estratégias de enfrentamento e intervenções em crises psicológicas (Ho et al., 2020).

$\mathrm{O}$ atendimento psicológico online tem se mostrado uma ferramenta virtual atrativa no que tange a impossibilidade de contato presencial, devido ao período de quarentena. Alguns autores enfatizaram que a Terapia Cognitiva Comportamental (TCC), através da psicoeducação, ao ensinar o paciente a lidar com a doença, seja ela física ou mental, é uma possibilidade de intervenção para a população. Sendo reforçado, dentro da TCC, o fortalecimento das técnicas de relaxamento e respiração para o controle da ansiedade, contribuindo assim com o bem estar físico e psíquico (Ho et al., 2020).

Ho et al. (2020) sugerem que informações verdadeiras devem ser transmitidas por veículos oficiais, objetivando diminuir o impacto emocional negativo nas pessoas, o que pode resultar em menos ansiedade e menor incerteza sobre a pandemia. Manter a transparência quanto a fluxos nos serviços de saúde, vacinação, número de pessoas infectadas, áreas afetadas e casos recuperados também apresentaram efeitos positivos em níveis reduzidos de estresse e ansiedade (Wang et al., 2020).

Smith e Freedman (2020) reforçam a importância de usar as mídias sociais para tranquilizar a população e esclarecer sobre os motivos da quarentena de modo a evitar pânico e falsos rumores. Da mesma forma, Rubin e Wessely (2020) sugerem que quando o sentido da quarentena é bem explicado e relacionado com altruísmo, pode ter uma boa adesão e menor impacto psicológico.

Outra ferramenta muito importante citada por Ho et al. (2020), seria a divulgação de pequenos vídeos informativos de fácil entendimento, sobre gerenciamento do estresse e técnicas de relaxamento. Essa estratégia também é apontada por Wang et al. (2020) como fundamental, pois, em seu estudo, a população em geral com menor formação acadêmica apresentaram maior predisposição a desenvolver depressão. Com isso, o uso de mídias de conteúdo acessível atua como suporte para as pessoas com baixo grau de instrução, conferindo as autoridades governamentais a responsabilidade de disponibilizar para a população geral informações de saúde atualizadas e precisas sobre a situação epidemiológica da região (Wang et al., 2020).

No contexto das informações, a WHO (2020) também recomenda a busca por informações de fontes fidedignas e atualizadas, evitando assim as fake news. Mas, orienta que essa busca seja realizada uma ou duas vezes por dia evitando assim o "bombardeio desnecessário" de informações. De acordo com a organização, esse controle de informações ajuda a minimizar o medo e a controlar a ansiedade.

De acordo com Straub (2014), o apoio social é um fator de proteção que ajuda as pessoas a lidarem com situações estressantes de forma mais eficaz aumentando as respostas físicas do corpo a situações difíceis. Logo, ressalta-se a importância de recorrer a outros mecanismos não presenciais para entrar em contato com o outro e fortalecer o apoio social, como ligações telefônicas e chamadas de vídeo (WHO, 2020).

A WHO (2020) recomenda que neste momento deve-se manter rotinas e tarefas regulares sempre que possível e criando atividades em ambientes diferentes da residência, como atividades diárias, limpeza, canto, pintura e outras. Para as pessoas que estão em quarentena com familiares, a recomendação é manter a rotina familiar diária ou criar uma rotina, principalmente nos lares onde se tem a presença de crianças. 
Outro ponto importante levantado é a realização de atividade física, no qual pode ajudar no controle da ansiedade e na regularização do sono (WHO, 2020). Contudo, deve-se evitar estratégias de enfrentamento desadaptativas de se lidar com o estresse, como por exemplo, o uso de álcool e tabaco ou outras drogas, pois, ao longo prazo elas pioram o bem estar físico e mental (Straub, 2014; WHO, 2020).

\section{CONCLUSÃO}

É consenso na literatura que diante de uma emergência de saúde pública a quarentena ou isolamento social podem desencadear diferentes sintomas psicológicos. Os sintomas mais comuns apontados pelos estudos foram, principalmente, ansiedade, medo, raiva e estresse, que trazem sofrimento para as pessoas que passam por essa situação, podendo ser agravados ou instalados mediante a vivência da quarentena ou isolamento. Contudo, os estudos também apontaram que algumas estratégias podem ser adotadas tanto por pessoas da população em geral quanto por profissionais de saúde e líderes de comunidades para auxiliar no enfrentamento e também na prevenção, passando de atendimento psicológico online, a divulgação de pequenos vídeos informativos sobre o manejo de estresse e ansiedade até o apoio social necessário. Quando adotadas em conjunto, podem atuar como atitudes protetivas e minimizar os efeitos psicológicos do isolamento tornando esse momento menos causador de sofrimento psíquico.

Todos os autores declararam não haver qualquer potencial conflito de interesses referente a este artigo.

\section{REFERÊNCIAS}

BRASIL. Ministério da Saúde. Secretaria de Vigilância em Saúde. Centro de Operações de Emergências em Saúde Pública. Boletim Epidemiológico Infecção Humana pelo Novo
Coronavírus (2019-nCoV) - Semana Epidemiológica 16. Brasília: Ministério da Saúde, 2020.

BRASIL. Lei $\mathrm{n}^{\circ} 13.979$ de 06 de fevereiro de 2020 .

BROOKS, S. K.; WEBSTER, R. K.; SMITH, L. E.; WOODLAND, L.; WESSELY, S.; GREENBERG, N. e RUBIN, G. J. The psychological impact of quarantine and how to reduce it: rapid review of the evidence. The Lancet, 2020.

COOMES, E. A.; LEIS, J. A. e GOLD, W. L. Quarantine. CMJA. 2020.

GUO, Y.; CAO, Q.; HONG, Z.; TAN, Y.; CHEN, S.; JIN, H.; TAN, K.; WANG, D. e YAN, Y. The origin, transmission and clinical therapies on coronavirus disease 2019 (COVID-19) outbreak - an update on the status. Military Medical Research. v. 7, n. 11, 2020.

HO, C. S.; CHEE, C. Y.e HO, R. C. Mental Health Strategies to Combat the Psychological Impact of COVID-19 Beyond Paranoia and Panic. Annals of the Academy of Medicine. v. 49, n. 1, p. 1, 2020.

HOSSAIN, M.; SULTANA, A. e PUROHIT, N. Mental health outcomes of quarantine and isolation for infection prevention: A systematic umbrella review of the global evidence. PsyArXiv. 2020.

KIM, H.; YOO, S.; LEE, B.; LEE, S. e SHIN, H. Psychiatric Findings in Suspected and Confirmed Middle East Respiratory Syndrome Patients Quarantined in Hospital: A Retrospective Chart Analysis. Psychiatry Investigation. v. 15, n. 4, p. 355-360, 2018.

LIMA, C. K. T.; CARVALHO, P. M. M.; LIMA, I. A. A. S.; NUNES, J. V. A. O.; SARAIVA, J. S.; SOUZA, R. I.; SILVA, C. G. L. e NETO, M. L. R. The emotional impact of Coronavirus 2019-nCoV (new Coronavirus disease). Psychiatry Research. v. 287, 2020.

QIAN, M.; WU, Q.; WU, P.; HOU, Z.; LIANG, Y.; COWLING, B. e YU, H. Psychological responses, behavioral changes and public perceptions during the early phase of the COVID-19 outbreak in China: a population based cross-sectional survey. MedRxiv. 2020.

RUBIN, G J. e WESSELY, S. The psychological effects of quarantining a city. BMJ, 368, 2020.

SANTOS, I. A. e NASCIMENTO, W. F. As medidas de quarentena humana na saúde pública: aspectos bioéticos. Revista Bioethikos. v. 8, n. 2, 174-185, 2014. 
STRAUB, R. O. Psicologia da saúde: uma abordagem biopsicossocial. Artes Médicas: Porto Alegre. 2014.

SMITH, A. W. e FREEDMAN, D. O. Isolation, quarantine, social distancing and community containment: pivotal role for old style public health measures in the novel coronavirus $(2019-\mathrm{nCoV})$ outbreak. Jornal of Travel Medicine, p. 1-4, 2020.

VOSGERAU, D. S. R. e ROMANOWSKI, J. P. Estudos de revisão: implicações conceituais e metodológicas. Rev. Diálogo Educ. v. 14, n. 41, p. 165-189, 2014.
WANG, C.; PAN, R.; WAN, X.; TAN, Y.; XU, L.; HO, C. e HO, R. Immediate Psychological Responses and Associated Factors during the Initial Stage of the 2019 Coronavirus Disease (COVID-19) Epidemic among the General Population in China. Int J Environ Res Public Health. v. 14, n. 5, 1759, 2020.

WORLD HEALTH ORGANIZATION (WHO). Mental Health and Psychosocial Considerations During COVID-19 Outbreak. 2020. 